LA RECONVERSIÓN

TECNOLÓGICA Y SUS

\section{EFECTOS SOBRE LA}

ESTRUCTURA DE LOS

\section{MEDIOS AUDIOVISUALES}

EN LA ERA DIGITAL

\section{Antonio García Martínez}

\author{
Profesor \\ Facultad de Ciencias de la Información. Universidad Complu- \\ tense de Madrid. Ciudad Universitaria, 28040 Madrid (España) \\ - Email: agama@ccinf.ucm.es
}

\section{Pedro Antonio Rojo Villada}

\section{Profesor}

Facultad de Comunicación y Documentación. Universidad de Murcia. Campus Universitario de Espinardo, 30100, Murcia (España) - Email: aparojo@um.es

\section{Resumen}

El ámbito audiovisual es un macrosector muy complejo que engloba sectores tan diversos como el de la producción de contenidos (con sus particularidades culturales y artísticas), el de las telecomunicaciones (con su reconversión tecnológica, competitividad y obligaciones de servicio público), el de los medios de comunicación social, Internet y los servicios de la sociedad de la información. Este artículo analiza las

\section{Palabras clave}

Convergencia, digitalización, reconversión, Internet, medios audiovisuales, producción, distribución, consumo

Key Words

Convergence, scanning, conversion, Internet, audiovisual media, production, distribution, consumption

\section{Abstract}

The audiovisual field is a very complex macro area that includes sectors as diverse as the production of contents (with all their cultural and artistic particularities), telecommunications (with their technological conversion, competitiveness and

public service obligations), social media, the Internet and Information Society services. This article examines the implications of the process of technological and market convergence for the computing, telecommunications, consumer electronics and audiovisual production sectors. It also traces the way an important part of the audiovisual content begins to be distributed through the networks as IP packages which will soon be offered commercially in information services tailored to both fixed and mobile terminals. Digitally distributed contents not only do offer information, but also provide an added value depending on both the information recipients' specific settings and reception times. As a result, the 
consecuencias del proceso de convergencia tecnológica y de mercados entre los sectores de la informática, las telecomunicaciones, la electrónica de consumo y la producción audiovisual, y también analiza como una parte importante de los contenidos audiovisuales comienzan a distribuirse por las redes en forma de paquetes IP y pronto se ofrecerán comercialmente en servicios de información adaptados a los terminales fijos y móviles. Los contenidos distribuidos digitalmente no solamente ofrecen información, sino también valor añadido en función del contexto en el que se encuentren los usuarios que reciben la información y el instante temporal de la recepción. Como consecuencia, en los próximos años, se abrirán camino nuevas formas de distribución audiovisual que no sólo van a cambiar las pautas del consumo de medios, sino que modificarán el propio concepto de medio de comunicación, ya que los medios convencionales equiparables a las empresas informativas tenderán a perder influencia frente a las redes sociales procedentes de iniciativas no necesariamente empresariales y también frente al empuje de los medios digitales personalizados. coming years will bring new forms of audiovisual distribution that not only will change media consumption, but will also alter the concept of mass media itself, since the conventional media comparable to information enterprises will tend to lose influence faced to the social networks coming from initiatives not necessarily belonging to the business sector and to the thrust of customized digital media.

\section{Introducción}

Presentamos en este artículo un trabajo exploratorio centrado en la evolución tecnológica del sector audiovisual. Este trabajo exploratorio antecede a un posterior trabajo de campo en el que se analizarán cuantitativamente unas variables determinadas sobre el sector audiovisual. Precisa- mente el sector audiovisual español es nuestro objeto de análisis y desarrollo en el presente artículo en el que tras analizar la bibliografía y documentación preexistente desarrollaremos una serie de tendencias que marcarán la evolución futura del sector en su transición hacia un escenario digital.

\section{Objetivos}

El objetivo de este artículo es el de conocer el contexto y las tecnologías que permiten producir, difundir y recibir los contenidos de los medios audiovisuales tras el proceso de digitalización y convergencia tecnológica. Este objetivo fundamental se puede descomponer en los siguientes objetivos:
1. Enumerar las diferentes tecnologías que permiten producir, difundir y recibir contenidos audiovisuales en la era digital.

2. Analizar los cambios producidos en el consumo de los contenidos y en el propio rol del consumidor que ahora 
ejerce un papel mucho más participativo en la difusión del contenido. sión digital sobre los modelos de negocio de los medios audiovisuales.

3. Explicar las consecuencias que tendrán las distintas modalidades de difu-

\section{Metodología}

Para lograr los objetivos señalados con anterioridad hemos desarrollado en el presente artículo un estudio exploratorio en donde hemos analizado la bibliografía y la documentación existente hasta la fecha y que más se aproxima al objeto de nuestra investigación (lo que incluye informes, artículos científicos, resultados de proyectos de investigación, etc.). Este estudio exploratorio se ha centrado en la evolución de la tecnología en el ámbito audiovisual con relación a la evolución que los propios medios audiovisuales también han sufrido en la última década.

\section{El peso del sector audiovisual}

El tradicional sector audiovisual -con la radio y la televisión- desempeña un papel fundamental en las sociedades democráticas tanto por su influencia política, social y cultural como por su volumen de mercado (Pérez, 2005: 4). La televisión abierta y gratuita se rearma mediante la tecnología digital terrestre (TDT) para contener el avance de otros medios, aún jóvenes, pero que podrían disputarle la corona en la transición a la sociedad de la información (Calzón, 2006: 57). La televisión digital ha pasado de ser un concepto tecnológico a ofrecer servicios reales disfrutados por millones de usuarios en todo el mundo. Las transmisiones por cable y por satélite si- guen siendo muy importantes, pero cada vez hay más interés por la televisión digital terrestre (DTTV) utilizando los sistemas DVB-T y ATSC (Marie y Cloirec, 2000: 48). El audiovisual se encuentra en una etapa de profunda reconversión, tras el proceso de digitalización. El sector clásico está compuesto por las actividades de difusión tradicionales:

- La radio y la televisión terrestre en abierto

- La televisión terrestre codificada

- La televisión de distribución directa por satélite, abierta o codificada

- La televisión por cable. 


\section{Viejas y nuevas formas de distribución audiovisual}

Actualmente, el impacto en la opinión pública de la televisión terrestre sigue siendo importante como servicio público; sin embargo, dicho concepto pierde fuerza a medida que la televisión pierde peso entre la audiencia a favor de otros medios y a medida que el desarrollo tecnológico se extiende junto a las nuevas redes digitales. Estas nuevas tecnologías son aceptadas como una revolución que cambiará radicalmente los medios de comunicación dominantes cuando no los arrasará en poco tiempo (Bustamante, 2001). El cambio tecnológico planteado no tiene precedentes en la historia de los medios audiovisuales. Por ejemplo, el sistema de televisión digital terrestre no era compatible con el sistema de televisión analógica, por lo que fue preciso establecer un período de transición donde coexistieron ambos servicios, de modo simultáneo, para que el usuario adaptara o renovase su equipo de recepción a la nueva tecnología, antes del apagado definitivo de los servicios analógicos (Pellicer, 2001: 94).

La distribución audiovisual admite una amplia variedad de posibilidades. Sin embargo el canal de distribución se asocia, a veces, a tecnologías específicas que condicionan el propio contenido. La distribución audiovisual estaba sometida a una situación de transición entre el mundo analógico y el digital (del tipo IP), donde algunas soluciones desaparecen frente a otras que evolucionan. Los sistemas tradicionales de distribución se basaban en la exhibición de contenidos o en la distribución de soportes físicos (cintas de video, DVDs, videodiscos digitales, etc.). En la actualidad, sin embargo, los contenidos no son estrictamente audiovisuales (música y video) sino informáticos (software) $\mathrm{y}$, cada vez más, multimedia (videojuegos, etc.). La televisión digital y, en general, las nuevas redes de comunicación son presentadas con frecuencia como una ruptura total (Bustamante, 2001). El carácter inmediato e interactivo de Internet, además de la tecnología en la que se basa, permite conocer de cerca a los visitantes, ahora bien, se necesitan métodos para cuantificarlos, porque no todo vale. Lo realmente importante para una página web es disponer de recuentos exhaustivos de visitantes. Este requisito resulta fundamental, puesto que es indispensable conocer el tráfico que se origina en un sitio, del mismo modo que hay mediciones de audiencia en otros medios como la televisión y la radio.

Otras modalidades de distribución son aquellas basadas en redes de telecomunicación, bajo la forma de servicios de televisión (terrestre, por satélite o por cable), telecomunicación, mediante sistemas de 
comunicaciones de telefonía fija o móvil y, por último, Internet como sistema integral, universal y flexible que amenaza a convivir, a corto plazo y quizás, a sustituir a los sistemas de distribución antes citados. Los hábitos de consumo digital, como la afición al podcasting y el acceso a Internet desde dispositivos móviles, van acaparando mayor protagonismo en el consumo de medios por parte de los españoles (Interactiva (c) 2007: 34).

Las plataformas digitales por satélite utilizan los contenidos procedentes de la televisión convencional, aunque con diferente forma de comercialización. Desde este punto de vista, la verdadera revolución no parece ser el paso del analógico al digital, sino la confirmación de un sistema de pago por ver la televisión (Becerro, 2002). Entre las características que acompañan a la televisión digital se encuentran sus posibilidades de interacción, si bien la interactividad ya se fue planteando desde los inicios de la televisión analógica (Pestano, 2003). El uso de Internet, en los próximos años, potenciará la actual demanda: fuente de información, de entretenimiento y de consumo. Se ha comprobado que "la red" puede afianzar los hábitos ya adquiridos, pero también se advierte que resulta cada vez más difícil crear otros nuevos. No ocurre lo mismo con las tecnologías que están permitiendo que accedamos a la red, a través de la telefonía móvil o de la televisión, para las que se crean contenidos específicos (Sandoval, 2000).

\section{Cómo afrontan los medios audiovisuales la reconversión tecnológica en la era di- gital}

Ya desde principios de siglo, venimos apuntando, de manera significativa, que la sociedad y los sistemas de comunicación evolucionan juntos y en muchos casos de manera inesperada. Ahora bien, los medios audiovisuales están basándose en patrones tradicionales por lo que el cambio no se notará sino en la calidad de imagen fundamentalmente. Ahora bien, las tecnologías de la información que diseña y desarrolla la industria audiovisual no siempre logran el éxito de su implantación en el mercado. Las razones de ello son numerosas:

- Insuficiencia de la propia tecnología.

- Incapacidad de la industria.

- Competencia de otros sistemas.

- Rechazo por parte del usuario.

Además, hemos de tener en cuenta que en el desarrollo de una tecnología siempre se estudian varias soluciones técnicas en paralelo y no una sola. Después, la mayoría 
fracasan y solo unas pocas penetran con éxito en el mercado.

Televisión y ordenador se unen en la era digital para ofrecer un producto diversificado con nuevos planteamientos de relación con el receptor. Los contenidos de televisión cambian cuantitativa y cualitativamente. Se crean pautas publicitarias distintas. El público pasa de ser audiencia a ser usuario, en una nueva relación bilateral con la pantalla. La interactividad es la clave (Millán, 2005: 82).

La comunicación está cambiando porque los mercados son conversaciones y los consumidores tienen el poder sobre ellos, generando contenido, compartiéndolo, expandiéndolo, buscándolo y consumiéndolo. Por ejemplo, YouTube, rompe el modelo de distribución de contenido audiovisual centralizado y se asemeja a un modelo de televisión a la carta, en el que el consumidor es a su vez autor y programador de la parrilla. No obstante, el fenómeno YouTube, no hay que contemplarlo como algo aislado. Internet es el verdadero fenómeno al posicionarse como un canal alternativo de comunicación publicitaria. El marketing viral y la publicidad viral refieren a las técnicas de marketing que intentan explotar redes sociales preexistentes para producir aumentos exponenciales en conocimiento de marca, con procesos similares a la extensión de una epidemia. El término de marketing viral fue acuñado originalmente para describir la práctica de varios servicios libres de correo electrónico de añadir su publicidad al correo saliente de sus usuarios (Interactiva, 2006: 10). Concretamente, el impacto de Internet en los medios audiovisuales se hará patente en los siguientes aspectos:

1. Mercado.

2. Contenidos.

3. Tecnología.

4. Organización.

La "cadena de valor" de los medios audiovisuales se verá sacudida por un amplio abanico de soportes, plataformas y dispositivos de acceso ofrecidos por los canales de distribución o difusión existentes o los nuevos que se desarrollarán en el futuro. En este escenario cambiante el papel y la dinámica de los agentes en la cadena del valor también cambiará, así como las diferentes modalidades de distribución de los contenidos y sus tecnologías. La televisión digital ha pasado de ser un concepto tecnológico a ofrecer servicios reales disfrutados por millones de usuarios en todo el mundo. Concepción integral, analítica y metodológica, que representa, a través de una cadena o conjunto de eslabones, una visión integral del ciclo económico-financiero y productivo de una empresa. Se recogen en la misma desde los proveedores de la empresa y las actuaciones previas a la actividad productiva, hasta las operaciones relacionadas con los clientes, actuaciones de servicio de asistencia y post-venta. La cadena de valor fue descrita y popularizada por Michael Porter en su best-seller de 1985: 
Competitive Advantage: Creating and Sustaining Superior Performance (Marie y Cloirec, 2000: 48).

Las audiencias y los usuarios de los medios audiovisuales -oyentes, telespectadores e internautas- como destinatarios finales de los productos o servicios audiovisuales se verán sacudidos por el impacto de las nuevas tecnologías en su dimensión social, económica y cultural. Los factores de entorno de tipo político, legal o económico también condicionarán o determinarán el desarrollo de los medios de comunicación audiovisual en el futuro, a medio y largo plazo.

\begin{tabular}{|c|c|}
\hline $\begin{array}{r}\text { Figura } n^{\circ} 1: \text { Ventanas } \\
\text { de una pelíc }\end{array}$ & xplotación \\
\hline 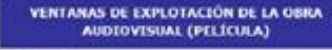 & Comienuro (daración) \\
\hline Solus deenta & Drmefiata (6-8 menes) \\
\hline DVD y siouler & 6.8 meses (3-6 meses) \\
\hline Drrat vew, Hatatornu inioal & 2-14 raeses (3 meses) \\
\hline TV de wose (12+ vertana) & $12 \cdot 17$ entses (6 mines) \\
\hline TV de page (so vertava) & 10-23 mines (6 mests) \\
\hline TV en abiorto & Indefinica \\
\hline \multicolumn{2}{|c|}{ Fuente: $C M T$} \\
\hline
\end{tabular}

\section{Transformación en la estructura de los medios audiovisuales}

Actualmente, los medios de comunicación audiovisual están sufriendo un proceso de transformación debido al impacto de las nuevas tecnologías de la información, en especial de Internet. Estos cambios están repercutiendo en ámbitos específicos: su estructura económica y de mercado, programación y contenidos, tecnología y aspectos sociales y organizativos.

En cuanto a su estructura económica y de mercado en el futuro continuará el proceso de concentración de los medios audiovisuales en grandes grupos de comunicación multimedia. Esta tendencia se verá impulsada por la necesidad de estos para conseguir la talla necesaria para poder competir en el mercado. Por otra parte, el hecho de tener que procesar información en diferen- tes formatos para distintos medios, exigirá una creciente capacidad multimedia por parte de dichos grupos, a la vez que requerirá la generación de sinergias entre sus diferentes divisiones. La concentración de los medios tendrá un carácter multinacional y multimedia, y servirá para hacer frente a crecientes presupuestos y nuevos mercados globales.

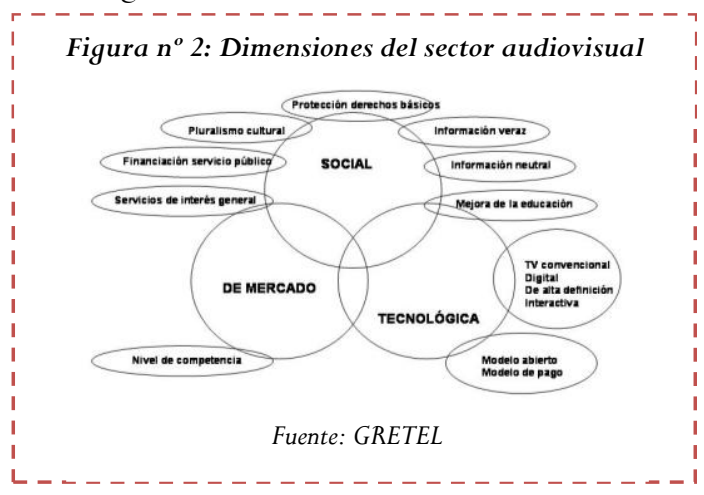




\section{La estrategia multiplataforma: ¿Puede aumentar la rentabilidad publicitaria de las empresas audiovisuales?}

La marca continuará siendo un factor clave para el éxito en el mercado audiovisual. El éxito de las empresas de comunicación pasará por crear marcas diferenciadas de productos, que serán utilizadas en plataformas múltiples. En lo que hace referencia al modelo de negocio, la publicidad continuará siendo la principal fuente de ingresos, aunque no la única. De hecho, actualmente ya se están potenciando otras fuentes, como el pago por visión o por la descarga de contenidos, cuya naturaleza depende del medio de que se trate. Asistimos a una nueva forma de hacer y ver televisión y radio, donde la publicidad se aliará a la interactividad para ofrecer valor a los radioyentes y espectadores (Interactiva, 2006: 43).

Una tendencia general, que ya es patente en la actualidad, es que la publicidad se reparta cada vez más entre un mayor número de agentes presentes en los diferentes mercados. Estamos asistiendo a una creciente lucha y competencia entre los medios audiovisuales para captar una parte del presupuesto destinado a publicidad de los anunciantes, que se distribuye habitualmente en diferentes soportes. Esta tendencia va a continuar en el futuro, siendo presumible que los nuevos medios, como Internet o el móvil, entre otros, capten una porción creciente de dicho presupuesto a medida que se consolide su presencia en el mercado, con lo que se reducirán paulatinamente los ingresos publicitarios de las empresas de televisión y radio.

En lo que se refiere a los contenidos publicitarios, se prevé que los medios generalistas capten en mayor medida la publicidad relativa a productos de consumo o masivos, mientras que las marcas de productos más especializados o dirigidos a determinados estratos sociales se decanten por publicitarlos en programas y medios de nicho. La metamorfosis que gradualmente está sufriendo la publicidad en el contexto de la televisión digital e interactiva depende de la comprensión de la interactividad, de la tecnología y su avance, y de la creación de contenido como servicio, y cómo afectará a las formas y a las funciones dentro del negocio publicitario. Se puede definir como la práctica de crear prestigio y valor a un producto/servicio con apoyo del marketing de marca, que puede estar asociado o no al nombre de una empresa (Carrillo, 2005: 33).

Otra de las tendencias que se vislumbran, y que también ya se detectan en la actuali- 
dad, es que la publicidad se orientará progresivamente hacia la promoción de los valores de una marca, más que hacia la venta de las características del producto en sí, de forma que la publicidad estará cada vez más vinculada al branding de la empresa fabricante, que busca identificar a la marca con los valores que representa. Por este motivo, las estrategias de publicidad van a ser más complejas, abarcando aspectos más amplios, tales como la promoción de los valores del producto, las relaciones públicas, los patrocinios, etc. Las transacciones comerciales como fuente de financiación de los medios audiovisuales se van a incrementar más en el futuro, especialmente en un entorno digital.

En cuanto a la programación y contenidos, cada uno de los medios de comunicación existentes ha tenido tradicionalmente una función primaria y unos usos específicos por parte de la sociedad. Estos usos sociales en el caso de los medios audiovisuales coinciden con su función de entretenimiento marcado por su carácter visual. A pesar de los años transcurridos y de los avances tecnológicos que se han producido la programación no ha variado sustancialmente. Lo que sí ha cambiado ha sido la cantidad de la oferta y la presentación al público: ahora por áreas temáticas (Fernández e Ibáñez, 1999). En el caso de los medios audiovisuales, su negocio seguirá desarrollándose sobre la base de las necesidades de ocio y espectáculo de la población. No obstante, el progreso tecnológico conti- nuado y la entrada de nuevos medios transformarán estos usos sociales de forma considerable y es posible que todavía lo hagan más en el futuro. Normalmente se asocia la revolución digital con la aparición de medios en línea, sin embargo la transformación ocurrida en los medios tradicionales, y en ellos hay que incluir a la radio, afecta a todos los niveles, desde el proceso de producción hasta la relación con la audiencia, con la fuente y con el mismo hecho noticioso (Blanco, 2005: 100).

Uno de los aspectos en los cuales se manifiesta este impacto es en la modalidad de difusión. En efecto, los medios de comunicación actuales están diseñados, en su mayoría, para difundir sus contenidos hacia el conjunto de sus usuarios, es decir, en la modalidad de uno a muchos. El desarrollo de la tecnología permitirá al usuario discriminar contenidos para acceder exclusivamente a aquellos que le interesen, personalizando de esta forma el canal de información. En la sociedad actual podemos estar conectados en cualquier lugar del mundo: basta llevar en el bolsillo un pequeño aparato que se convirtió en los últimos años en la gran estrella de la población: el teléfono móvil (Ueda, 2004).

Los nuevos medios de comunicación se basarán entonces en el concepto de "uno a uno", en lugar del tradicional "uno a muchos", con lo que los modelos de negocio de las empresas audiovisuales van a tener que cambiar radicalmente. El núcleo de este cambio va a estar en la transición des- 
de un modelo de negocio basado en un enfoque de oferta, que se podría traducir como "consumir la programación y los contenidos que nos ofrece la televisión o la radio como medio masivo", a un modelo de negocio basado en el enfoque de demanda, que se caracterizará por "la selección del contenido que más interese de acuerdo con las necesidades y las preferencias de los usuarios”.

Las tecnologías digitales, unidas a una oferta creciente y diversificada, van a hacer posible este cambio de paradigma que comportará que el poder de selección de los contenidos se traslade cada vez más a los usuarios. Este factor tiene, como es lógico, consecuencias muy importantes para el modelo de negocio de la industria audiovisual. Una transformación tan radical va a permitir, entre otras actividades, la realización de transacciones comerciales en línea con el usuario de forma más amplia y generalizada o el contacto entre el usuario y los anunciantes. En éste contexto digital tienen mucho que decir los propios agentes, ya que cuentan con intereses distintos (Aznar, 2002).

Por otra parte, ya comienzan a proliferar los medios y programas de nicho, que ofrecen y seguirán ofreciendo nuevos contenidos dirigidos a grupos sociales o profesionales determinados. En este caso, los contenidos locales, deportivos y de ficción dirigirán la programación. Este nuevo enfoque planteará problemas a los usuarios en cuanto a qué contenidos elegir y cuánto se está dispuesto a pagar por ellos (Bustamante y Álvarez, 1999). En el lado de los operadores, la lucha se centra en la posesión de los derechos de emisión sobre determinados contenidos (los más atractivos para las audiencias como el fútbol o las películas). La implantación de estos contenidos ya se lleva a cabo mediante plataformas de productos diferenciados que se ofrecen en forma de paquetes, con el fin de facilitar su elección y conocer a priori su coste por parte de los usuarios (especialmente en los casos de la televisión digital por satélite o de la televisión por cable).

La telefonía móvil $3 \mathrm{G}$ resume unas enormes expectativas en cuanto a nuevos servicios móviles como, por ejemplo, la transmisión de fotos, la televisión móvil, videollamada, música o la navegación de calidad por Internet. Esta tecnología comenzó con expectativas demasiado optimistas y siguió con un periodo de decepción motivado por la falta de inversiones de los operadores, la ausencia de terminales $3 \mathrm{G}$ a precios asequibles y, sobre todo, la falta de contenidos o servicios. Uno de los elementos clave para el desarrollo del negocio será el precio de los nuevos servicios 3G. Los operadores móviles tienen que mantener un equilibrio adecuado entre la elevada rentabilidad del modelo de ingresos actual y las también elevadas inversiones que requieren las redes $3 \mathrm{G}$.

De hecho, una evolución radical hacia tarifas planas sin limitaciones de consumo puede suponer una amenaza para el nego- 
cio actual de las operadoras móviles al poder dirigir también el tráfico de voz a través de Internet (mediante el protocolo VoIP). Por todo ello, las decisiones sobre el precio de $3 \mathrm{G}$ y la posibilidad de acceder de forma libre a Internet desde los móviles tienen implicaciones estratégicas de primer nivel y no es esperable una ruptura radical del modelo actual de precios sin una etapa larga de transición. La 4G hace referencia a las tecnologías que permiten el uso indistinto de redes fijas y móviles en función de la ubicación del usuario, combinando cualquier modo de acceso que permita un suficiente ancho de banda y a través del protocolo de comunicación común de Internet (IP). 4G no es, por tanto, la evolución directa de $3 \mathrm{G}$. Se trata más bien de una forma de denominar el proceso de convergencia que está ocurriendo en el sector de telecomunicaciones fijas y móviles gracias al ancho de banda y al protocolo de Internet (Boletín de Estudios Económicos, 2005: 471).

\section{El rol de los contenidos ante la abundancia de la oferta audiovisual}

La industria de ficción conoce actualmente un éxito sin precedentes. Series y seriales ocupan las mejores franjas horarias en las parrillas de programación y son seguidos por una audiencia fiel y numerosa. A este fenómeno ha contribuido la aparición de nuevos yacimientos y soportes publicitarios en un entorno de competencia televisiva, las políticas de externalización, la contención del gasto y la innovación de las cadenas y la progresiva profesionalización de los equipos creativos. Sin embargo, y pese a que la inversión en estos formatos se ha duplicado en los cinco últimos años, el sector de la producción soporta serias debilidades derivadas de su extrema dependencia de las cadenas. La llegada de las nuevas ofertas del cable y de la televisión digital terrestre podría suponer el fortalecimiento de las estructuras financieras e industriales de las productoras (Álvarez y López, 1999).

Por lo que respecta a la tecnología, los nuevos medios audiovisuales presentarán una emisión multicanal en el entorno digital, lo que les permitirá explotar y rentabilizar una gran cantidad de contenidos audiovisuales almacenados y ya utilizados. La irrupción de Internet en los medios audiovisuales representará un salto cualitativo determinante en este sentido y dará lugar a que algunas departamentos, incluidas las redacciones, experimenten una transformación profunda en los modos de operar o difundir los contenidos. Por otra parte, los contenidos que se deberán procesar y transmitir los medios audiovisuales serán de naturaleza multimedia en la mayor parte de las ocasiones (incluyendo textos, gráfi- 
cos, audio y vídeo). Ello implicará que todos los eslabones de la cadena de producción utilicen sistemas multimedia en la mayor parte de sus actividades.

Por otra parte, se tenderá hacia una modalidad de "emisión participativa", en la que se dejará sentir de forma notoria la "opinión del usuario" (telespectador u oyente). De esta forma se tendrá cada vez más realimentación de las necesidades e intereses de la demanda. La emisión, por su parte, se adaptará al soporte al que vaya destinada, de entre los diferentes formatos disponibles. De hecho, por motivos de productividad los contenidos se diseñarán en origen para ser adaptados rápida y fácilmente a diferentes formatos multimedia.

Por otra parte, se prevé la implantación, a largo plazo, de una nueva generación de medios de comunicación basados en el acceso a la banda ancha, tanto por medio de terminales fijos como de dispositivos móviles. Una de las características más destacadas de dicha generación será la posibilidad de conexión y actualización permanente en línea de los contenidos y el consumo por parte de un usuario desplazándose hacia su lugar de trabajo, ocio u hogar. En este caso, los usuarios recibirán el contenido mediante sistemas móviles en el momento en que se produzca.

La transmisión de televisión y el vídeo por ADSL, la televisión móvil y la televisión por Internet mediante conexiones de banda ancha interfieren con el desarrollo de la TDT. Los modelos convencionales basados en el gusto de las mayorías y en la guerra de audiencias, donde todos se copian, también deben superarse con la nueva oferta de televisión digital interactiva (Aguado, 2006: 10). Tras varios intentos fallidos, la televisión interactiva (TVi) afronta un nuevo relanzamiento en varios países, propiciado por el entorno de convergencia entre los medios audiovisuales e Internet. En las últimas décadas, se han desarrollado diversas pruebas de mercado e incipientes servicios comerciales de televisión interactiva. Aunque la mayoría han resultado fracasos comerciales, su experiencia ofrece una valiosa información, que resulta de gran valor para analizar la situación presente y las perspectivas de futuro de este nuevo medio (León y García, 2002). En este sentido, las compañías telefónicas han encontrado un nicho de mercado que no quieren dejar escapar, por ello las operadoras vienen apostando por entrar de lleno en la producción audiovisual, un negocio que crecerá en los próximos años, con las ofertas que aporta la televisión digital terrestre, las plataformas de televisión de pago, así como las soluciones de internet. Esta apuesta de las empresas telefónicas por lo audiovisual lleva aparejado convenios, lo cual garantiza una colaboración en ambas direcciones, tanto de contenidos como de publicidad. 


\section{La reconversión tecnológica en la radio: nueva estructura organizativa}

La radio digital diversifica y aumenta los canales de distribución de los programas de radio, incluye nuevos contenidos diferentes al sonido y crea otras formas de diálogo con la audiencia. Por lo tanto, modifica el modelo tradicional de radiodifusión y plantea grandes desafíos en el terreno de los contenidos y la gestión de las empresas de radio (Martínez, 2004: 9). La era digital desplaza muchas fronteras y hace surgir nuevas competencias: los proveedores de acceso, los distribuidores de servicios, etc. La labor de las emisoras de radio se vuelve claramente la edición de contenidos. Pero, los mismos contenidos, tienden a evolucionar de muchas maneras como lo muestra el inventario de programas disponibles para todos los soportes digitales existentes. Entre los cambios que la revolución digital ha introducido en nuestros modos de entender la radio, se pueden señalar de manera sintética al menos tres paradigmas de evolución (García: 2005):

- La transformación en el modo de ofrecer los contenidos, del flujo de programas a programas en stock.

- El cambio de los formatos temáticos a los servicios a la carta personalizados.

- La radio por los ojos: el audio y los datos multimedia.
La implantación de la radio digital se desarrolló de manera desigual: por una parte, a pesar del impulso de los foros internacionales para buscar nuevas vías para la comercialización, fue, y es, necesaria una fuerte inversión para crear el parque de receptores digitales; por otra, la radio digital tiene que competir y coexistir con la radio analógica, fuertemente establecida en el mercado. A pesar de sus dificultades, el DAB ofrece grandes ventajas frente a la radio analógica: mejor calidad de recepción, la posibilidad de información adicional, la liberación del radioespectro y el aumento de ofertas de programas, lo que supone un nuevo reto para los profesionales y las empresas radiofónicas (Peñafiel, 2004: 16).

Los cambios que se están originando en la radio en general y en el trabajo de los periodistas de radio, derivan, fundamentalmente, de la conversión de Internet en un medio masivo de difusión de información periodística. En primer lugar, la radio, como medio periodístico tradicional, ha tenido que variar su estrategia para acomodarse a la aparición de un "nuevo medio" y competir en la red con el desarrollo de nuevos productos. En segundo lugar, los periodistas de radio han de usar todos los elementos técnicos que tengan a su alcance, 
pero no deben olvidar que lo realmente importante de su trabajo es comunicar la información. El control, por parte de los periodistas, de los contenidos informativos, de carácter periodístico, es la única forma de garantizar la calidad, objetividad, veracidad y credibilidad de la información (Canga, 2001: 35).

El proceso de implantación del sistema digital en la radio no se ha consolidado, a pesar de que este sistema ofrece mejoras en la calidad del sonido, elimina las interferencias y puede optimizar el espectro radioeléctrico, al combinar diversas ofertas programáticas en un sólo bloque, utilizando un único transmisor (Franquet y Ribes, 2004). La radio ha tenido que adaptarse a las exigencias que la misma competencia tecnológica le impone. Pero el reto es cómo abordar los contenidos del medio audiovisual y en especial de la producción radiofónica. En el caso de la tecnología digital es el mismo mercado el que va imponiendo el paso de su aplicación, por lo que el consumidor y el productor del medio audiovisual terminan por adaptarse a su uso sin mayores miramientos. No se puede decir lo mismo en el caso de los contenidos que se ofrecen a través del medio radiofónico, ya que sería una utopía pensar a corto o mediano plazo en la desaparición de la radio analógica. En un medio digital como Internet, por ejemplo, los consumidores buscan un mensaje más fluido y con menos esfuerzo de recepción. En general se ha prestado muy poca atención al reto que supone la digitalización del medio porque son pocas o nulas las experiencias desarrolladas en ese sentido por dos factores:

- Al receptor no se le ha vendido la idea de la radio digital y las posibilidades que la misma le ofrecerá, por consiguiente nadie está pensando en sustituir su receptor analógico.

- El empresario de radio no ha visualizado las posibilidades de comunicación e información que ofrece el medio digital. Es más, en muchos casos no ve más allá de que la radio es un instrumento para generar ingresos a través de la programación local o musical.

Se ha iniciado la cuenta atrás para la radio, para dar el salto cualitativo que le permita hacer frente al nuevo entorno digital multimedia. Con la introducción de la tecnología digital en el proceso de producción, emisión y recepción, la radio tendrá una oportunidad para diversificar sus programas. En la mayor parte de las ocasiones es la propia audiencia, localizada entre los jóvenes, la que impone a la radio el cambio de la programación analógica a la digital, así como una constante actualización de contenidos y la posibilidad de interactividad con los receptores (Calzón, 2006: 56). La radio también tiene una buena posición de partida para enfrentarse a los cambios tecnológicos en el entorno cotidiano, debido a su capacidad de diversificación, personalización de la información y su entretenimiento, cualidades especialmente valoradas por los jóvenes y el ámbito musical. La 
radio deberá utilizar todo el potencial de las nuevas herramientas para personalizar más los contenidos de su programación. Debe aprovechar los recursos que le ofrece Internet con el chat, así como la comunicación móvil, recursos que ya se son explotados por la radio analógica. El podcasting consiste en crear archivos de sonido (generalmente en MP3 u ogg) y poder subscribirse mediante un archivo RSS de manera que permita que un programa lo descargue para que el usuario lo escuche en el momento que quiera, generalmente en un reproductor portátil (Interactiva (c) 2007: 34).

En la radio digital parece existir una unanimidad respecto del potencial de la revolución digital, pero también muchas dudas sobre las fórmulas y el calendario de im- plantación. ¿Por qué si existen emisiones digitales con cobertura prácticamente total en España desde hace ya varios años, sólo unos pocos miles de aparatos forman el parque de receptores domésticos? ¿No son asequibles económicamente porque no existen oyentes, o es al revés? ¿La interactividad sería el componente ideal, la aplicación estrella, para convencer a la persona usuaria e implementar, de este modo, el consumo de radio digital? El Foro de la Radio Digital se constituyó en enero de 1998 con el objetivo de impulsar el desarrollo de este medio en el Estado español y está constituido por radiodifusores públicos y privados, operadores de red y fabricantes de equipos emisores y receptores. La Administración también participa aunque no es un miembro activo.

\section{El retraso de la radio digital española}

Las infraestructuras para desarrollar la tecnología del DAB están a punto, pero aún no se han dado las condiciones favorables para que el proyecto arranque con éxito. Las primeras emisiones en digital se iniciaron a finales de la década de los noventa, aunque este sector todavía no ha visto la salida deseada al mercado porque la implantación de la tecnología DAB permanece estancada y a la espera del impulso necesario para establecerse y difundirse adecuadamente.
Una de las razones de más peso para pasar al sistema digital es la saturación del espectro en FM y el interés por conseguir nuevas audiencias. El punto de inflexión en el despliegue de la nueva tecnología se puede producir cuando se den las condiciones ideales: suficiente información al consumidor y un precio adecuado de los reproductores. Al explicar el estancamiento del DAB suele hablarse de un círculo vicioso: pocos compradores, receptores caros $\mathrm{y}$ pocos programas en DAB. Es evidente que la aparición del DAB representa una trans- 
formación substancial del sector radiofónico. El desarrollo del DAB depende, sobre todo, de la actitud de los radiodifusores. Si se quiere considerar el DAB como la radio del futuro, habrá que prever y asegurar a largo plazo la presencia de los difusores actuales en el nuevo dial digital con el mismo número de canales de los que disponen hoy en día.

En segundo lugar, los nuevos radiodifusores se deberían incorporar al nuevo dial de manera progresiva, en la medida en que el sector radiofónico los fuera integrando sin poner en peligro la estabilidad del sector. Por último, las emisoras locales podrían quedarse inicialmente en el dial de FM, que se iría descongestionando a medida que los radiodifusores de alcance estatal y autonómico migrasen hacia el $\mathrm{DAB}$, para que, en un futuro más lejano, las emisoras locales también migraran al DAB para abandonar la FM. Desde ese momento la radio analógica se convertiría en una tecnología totalmente obsoleta al lado del DAB.

Si tenemos en cuenta que el espectacular éxito europeo en el ámbito de la telefonía móvil se debe al establecimiento de una directiva europea que disponía la banda de frecuencias para uso exclusivo y obligatorio de la telefonía móvil digital, de una norma común para implantarla (GSM) y de una resolución de introducción coordinada del servicio, que nació con vocación paneuropea, sin semejante política coordinada no se logrará fácilmente introducir la radio digital. Así pues, la radio digital debe librar una batalla desigual en la que la analógica tiene las mejores armas: mejor precio de los receptores, el gran parque existente y la cantidad de contenidos difundidos. Las nuevas tecnologías y la televisión temática han creado un nuevo modelo televisivo europeo con multitud de canales y servicios interactivos.

Por otra parte, la radio actual se basa, mayoritariamente, en la existencia de cadenas de ámbito estatal (o nacional) con desconexiones locales. Aunque una parte importante de las concesiones digitales otorgadas posibilita un programa con desconexiones territoriales, el ámbito del territorio permitido para estas desconexiones abarca un área correspondiente a más de una comunidad autónoma, por lo que no tiene ningún interés para explotarlo comercialmente. La principal ventaja de la radio digital es la calidad de recepción, incluso con el receptor en movimiento. Al margen de la calidad, la radio digital tiene otras ventajas:

1. La posibilidad de difundir adicionalmente otras señales de datos. Entre los servicios añadidos al audio figuran la transmisión de una imagen fija en paralelo con la noticia hablada; la transmisión de imágenes de alta resolución gráfica; sistemas de información del tráfico con recomendaciones sobre caminos alternativos; sistemas de pago y transmisión de datos a grupos cerrados de usuarios (información sobre tarjetas 
de crédito, el tiempo, ofertas de ocio, etc.).

2. Más eficiencia espectral, con lo que se podría mejorar la cantidad y variedad de programas.

3. Posibilidad de organizar coberturas territoriales amplias con el uso de una sola frecuencia.

Desde fines de 1997 se dispone del marco legal básico que posibilita la introducción de la radio digital. Este marco establece que la introducción de la radio digital se basará en infraestructuras terrestres y permitirá ámbitos estatales, nacionales y locales gestionados de manera directa o indirecta mediante concesión administrativa. Ya se han otorgado concesiones según la norma DAB, lo que impide de facto la vía alternativa de la sustitución de la digitalización de la FM y la OM (Rodríguez, 2004: 27).

A través de la radio digital el contenido de la programación se puede usar y reempaquetar a través de diversas plataformas como radio, telefonía móvil e Internet, de manera que no solo surgen nuevas sinergias entre estas industrias antes separadas, sino que se multiplican las oportunidades de negocio transversal entre dichas plataformas (Burke, Capell y Reinhardt, 2005: 80).

El usuario puede almacenar programas de radio en el disco duro de su receptor, o en su reproductor digital de música, como el iPod, para la reproducción posterior, y además puede recibir la información básica sobre el título y el intérprete de una canción, y permitir su compra en línea, de igual manera que es posible personalizar el tipo de datos (clima, tráfico, bolsa de valores, titulares de noticias) que se pueden visualizar en la pantalla del receptor (Cortés, 2005: 74).

Para concluir, los parámetros fundamentales que definen a la radio española de la última década, desde un punto de vista básicamente estructural, serían los de: concentración, oligopolio, persistencia del sistema concesional y falta de desarrollo de la radio digital (Bonet, 2005: 62).

\section{Conclusiones}

1. En la última década y al amparo de la tecnología digital han surgido nuevos mercados audiovisuales propiciando una mayor multiplicación de la oferta y fragmentación de los consumidores.

2. En cuanto a las nuevas formas de distribución audiovisual se imponen aquellas dirigidas a un único usuario que, además, tiene la capacidad de interaccionar con el contenido. Por tanto parece que el modelo de difusión masiva, sin llegar a desaparecer, sí que está perdiendo paulatinamente importancia económica e influencia social. 
3. Los medios audiovisuales están modificando sus estructuras y modelos de explotación para hacer frente a la reconversión tecnológica. La transformación en la estructura de los medios audiovisuales afecta profundamente a la oferta de contenidos, apostando por una estrategia multiplataforma en busca de una dudosa rentabilidad publicitaria ante un mercado atomizado de oferta y cada vez con menos propensión al consumo por parte de consumidores atraídos por otras formas de ocio digital alternativas al consumo de medios.

4. La importancia de los contenidos en este nuevo entorno descrito en el apartado anterior ya no se basará exclusivamente en lo que los usuarios ignoran, sino en los beneficios prácticos que la información aportará a los usuarios en función de su contexto (lugar y espacio geográfico) y en función de su capacidad de interactuar y convertirse en promotores de información y generadores de opinión (actividades exclusivas hasta hace pocos años del medio como institución)

5. El retraso de la radio digital española se debe no solo a las incertidumbres propias generadas por la crisis del mercado publicitario y la pérdida paulatina de oyentes sino también a factores endógenos relacionados con la propia industria productora de aparatos de radio y la falta de una apuesta decidida de las empresas por cambiar el modelo de explotación tradicional del medio.

\section{Referencias}

AGUADO, G.: "La televisión europea del futuro". MK: Marketing + ventas, Año 21, $\mathrm{n}^{\circ} 219,2006$, pp. 8-11.

ÁLVAREZ, J.M.; LÓPEZ, J.: "La producción de ficción en España: en cambio de ciclo”. Zer: Revista de estudios de comunicación, $\mathrm{n}^{\circ} 7,1999$. En http://www.ehu.es/zer/zer7/monzoncillo67.html

AZNAR, H.: "Televisión, telebasura y audiencia: condiciones para la elección libre”. Revista Latina de comunicación social, ISSN 1138-5820, $\mathrm{n}^{\circ} 48,2002$. En http: / /www2.ull.es/publicaciones/latina/2002/lat ina48marzo/4807aznar2.htm

BECERRO, S.: "Contenidos de la televisión digital por satélite en España”. Área abierta, no 2, 2002. http: / / www.ucm.es/info/ cavp1/Area\%20Abierta /AREA \%20ABIERTA \%202/articulos\%202/PDFbe ceiro.PDF
BLANCO, L. E.: "Nuevos periodistas para medios no tan nuevos". Comunicación: estudios venezolanos de comunicación, n 131, 2005, pp. 99-102.

BOLETÍN DE ESTUDIOS ECONÓMICOS:

"3G/UMTS: una realidad impaciente". Vol. 60, n 186, 2005, pp. 469-490.

BONET, M.: "La radio española 1994-2004: una década de consolidación y desencanto". Sphera pública: revista de ciencias sociales y de la comunicación, $\mathrm{n}^{\circ}$ 5, 2005, pp. 59-70.

BURKE, J.; CAPELL, K.; REINHARDT, T: "La televisión digital”. Dinero: inteligencia empresarial, $\mathrm{n}^{\circ}$ 942, 2005, pp. 80-81. 
BUSTAMANTE, E.; Álvarez Monzoncillo, J. M.: "España: la producción audiovisual en el umbral digital”. Zer: Revista de estudios de comunicación, $\mathrm{n}^{\circ} 7$, 1999. En http://www.ehu.es/zer/zer7/bustamante66.html

BUSTAMANTE, E.: "Impacto social del nuevo escenario audiovisual: retos y riesgos en la era digital". Área abierta, n ${ }^{\circ} 1,2001$. En http://www.ucm.es/info/cavp1/Area\%20Abierta /Publicaciones Area Abierta/PDFbustamante.PDF

CALZÓN, B.: “TDT en España: La televisión digital entona el "vini, vidi, vinci". Dinero: inteligencia empresarial, $\mathrm{n}^{\circ}$ 950, 2006, pp. 56-58.

CANGA, J.: "Periodismo e Internet: Nuevo medio, vieja profesión”. Estudios sobre el mensaje periodístico, $\mathrm{n}^{\circ}$ 7, 2001, pp. 33-48.

CARRILlO, M. V.: "La televisión digital. La metamorfosis publicitaria en el entorno interactivo". Telos: Cuadernos de comunicación, tecnología y sociedad, $n^{\circ}$ 62, 2005, pp. 31-41.

CMT: Comisión del Mercado de las Telecomunicaciones.

CORTES, C. E.: "La radio digital”. Revista Latinoamericana de Comunicación Chasqui, no 89, 2005 , pp. 70-77.

FERNÁNDEZ, E.; IBÁÑEZ, J. L.: “Televisión digital y programación: de la televisión de siempre a la televisión de pago y multicanal”. Revista Latina de comunicación social, $\mathrm{n}^{\circ} 14,1999$. En

http: / / www2.ull.es/publicaciones/latina/a1999c/ 130emilio.htm

FRANQUET, R.; RIBES, X.: "La transición digital pendiente de migración”. Área abierta, n 4, 2002. En http: / / www.ucm.es/info/cavp1/Area\%20Abierta /4\%20AREA \%20ABIERTA/articulos/franquet rib es.PDF

GARCÍA, A.: "La idea frente a la técnica: el valor de la persona en la radio digital”. Razón y palabra, $\mathrm{n}^{\circ} 42$, 2005. En

http: / / www.cem.itesm.mx/dacs/publicaciones/lo gos/anteriores/n42/agarcia.html

GRETEL: Grupo de Regulación de las

Telecomunicaciones. Colegio Oficial de Ingenieros de Telecomunicación. Madrid.
INTERACTIVA: "El móvil y la TDT, protagonistas en la investigación de medios: VI Encuentro AIMC sobre Investigación de Medios”, n 65, 2006, pp. 42 43.

INTERACTIVA: "Notoriedad ¡iipor un tubo!!! (You Tube)", no 72, 2006, pp. 10-14.

INTERACTIVA: "Internet sigue restando tiempo a la televisión”, nº 79, 2007, pp. 34-35.

LEÓN, B.; GARCÍA, J. A.: "Los retos de la implantación de la televisión interactiva a la luz de su propia historia”. Zer: Revista de estudios de comunicación, $\mathrm{n}^{\circ} 13,2002$. En http: / / www.ehu.es/zer/zer13/retos13.htm

MARIE, P.; CLOIREC, S.: "La TV digital terrestre en todo el mundo". Revista española de electrónica, $\mathrm{n}^{\circ}$ 544, 2000, pp. 48-50.

MARTÍNEZ, M. P.: "La radio digital en Europa: perspectivas y evolución”. Quaderns del CAC, $\mathrm{n}^{\circ} 18$, 2004, pp. 3-12.

MILLÁN, T.: "La televisión digital y sus repercusiones comunicativas: de públicos a usuarios”. Ámbitos: Revista internacional de comunicación, $\mathrm{n}^{\circ}$ 13-14, 2005, pp. 79-89.

PELLICER, V.: "Televisión Digital Terrenal TDT: El impulso necesario". Bit, n 147, 2004, pp. 91-92.

PEÑAFIEL, C.: "Cara y cruz de la radio digital en España”. Quaderns del CAC, $\mathrm{n}^{\circ} 18,2004$, pp. 13-22.

PÉREZ. J.: "La otra televisión digital”. Telos: Cuadernos de comunicación, tecnología y sociedad, $n^{\circ} 62$, 2005, pp. 4-5.

PESTANO, J. M.: "La digitalización de utopías: desarrollos y retos de la televisión interactiva”. Área abierta, $\mathrm{n}^{\circ}$ 5, 2003. En

http://www.ucm.es/info/cavp1/Area\%20Abierta /5\%20AREA \%20ABIERTA/articulos/pestano.PDF

RODRÍGUEZ, F.: "El sector analiza la radio digital”. Quaderns del CAC, no 18, 2004, pp. 23-31.

SANDOVAL. M. T.: "Medios de comunicación y publicidad en Internet”. Revista Latina de comunicación social, $\mathrm{n}^{\circ} 36,2000$. En

http: / / www2.ull.es/publicaciones/latina/aa2000kj $\underline{\text { l/u36di/10sandoval.htm }}$ 
UEDA, V.: "La gran estrella del siglo XXI: el teléfono móvil y sus múltiples territorialidades". Scripta Nova: Revista electrónica de geografía y ciencias sociales, $\mathrm{n}^{\circ} 170,2004$. En

http://www.ub.es/geocrit/sn/sn-170-7.htm

\section{Cita de este artículo}

GARCÍA MARTÍNEZ, A. y ROJO VILLADA, P. A. (2010) La reconversión tecnológica y sus efectos sobre la estructura de los medios audiovisuales en la era digital. Revista Icono14 [en línea] 1 de Julio de 2010, № Año 8, Vol. 2. pp. 136-155. Recuperado (Fecha de acceso), de http://www.icono14.net 